\title{
Asociaciones campesinas en resistencia civil. Construcción de paz y desarrollo en el Magdalena Medio
}

\author{
Peasants Associations in civil resistance, \\ construction of peace and development in the Magdalena Medio
}

Silva Prada, Diego. (2011) Corporación Universitaria Minuto de Dios. Bogotá. 251 páginas.

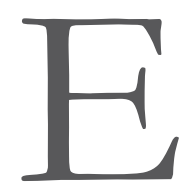
1 libro Asociaciones Campesinas en resistencia civil. Construcción de paz y desarrollo en el Magdalena Medio, de Diego Fernando Silva Prada, cuya presentación en público se realizó el pasado 12 de septiembre de 2012, tiene múltiples méritos. Me concentraré en destacar cinco de ellos.

Uno: El estudio se ocupa de un territorio rural, el Magdalena Medio. Una región que en medio de sus muchas riquezas es marginal en el país y que como suele pasar en otros lugares, crea sus propios centros y sus periferias. Los territorios de la Asociación Campesina del Valle del río Cimitarra (ACVC) y de la Asociación de Trabajadores Campesinos del Carare (ATCC) corresponden a esas márgenes del Magdalena Medio. Poner la lupa en estos contextos rurales, en sus historias y procesos de poblamiento y de construcción de lugar, que supone entrar en un mundo de gran diversidad, pese a la homogeneización que se ha construido sobre lo rural, como planos, repetitivos, simples y rutinizados.
Diego Fernando narra a lo largo de su texto, pero quizá con mayor detalle, toda la carga de la experiencia y la sorpresa del proceso mismo del conocer, en el primer capítulo. Allí va descubriendo las trochas, las distancias, los paisajes, las historias, las situaciones y condiciones, ese acercamiento a un mundo desconocido nos va confrontando como extraños, como foráneos, con nuestros propios esquemas de interpretación y de abordaje, a esas otras experiencias. Vamos descubriendo con la observación y con las historias las tristezas, las alegrías, la acogida de los pobladores, la posibilidad de conversar y de abrir su mundo con calidez, a veces incluso asombrados que alguien se interese en sus vidas.

El mundo rural nos depara muchas sorpresas. Hay allí una serie de claves para comprender quiénes somos y para dónde vamos como sociedad nacional. Los pobladores rurales, con toda su diversidad y capacidad, actores que poco aparecen en el reparto de la historia nacional, tienen mucho qué decirnos

1 Profesora Facultad de Estudios Ambientales y Rurales, Universidad Javeriana, Bogotá. fosorio@javeriana.edu.co. 
frente a nuestros pasado, a nuestro presente y a nuestro porvenir.

No puedo sustraerme a la tentación de preguntarme en voz alta, cómo y cuándo será posible que lo rural se vuelva protagonista de la vida nacional, para ser reparado, reconocido, valorado y dignificado, por fuera de intereses mezquinos que sólo lo reconocen para saquearlo, relegado secularmente a ser solo un botín de recursos. ¿Cómo leer, pero sobre todo, cómo se concretará efectivamente el desarrollo rural como punto central de las conversaciones de paz que apenas comienzan? Tal como lo han planteado varios estudioso y, más recientemente, el informe del PNUD, "Colombia rural: razones para la esperanza", publicado en 2011, el campo y su pobladores tienen inmensos obstáculos estructurales para posibilitar condiciones que dignifiquen la vida rural y la sitúen como una opción de vida posible y deseable. El modelo que ha prevalecido, dice el informe, no promueve el desarrollo humano y hace más vulnerable a la población rural; no promueve la sostenibilidad que concentra la propiedad rural y crea condiciones para el surgimiento de conflictos y es poco democrático, entre otros muchos problemas. En esta coyuntura, ¿cómo podremos hacer posible que la Colombia rural, que incluye al $75 \%$ de los municipios colombianos, a cerca del $32 \%$ de la población total y el $95 \%$ de la superficie del país, se constituya efectivamente en una buena razón para ofrecer la esperanza de esta sociedad, tan profundamente golpeada por el conflicto armado, máxime cuando ha sido precisamente la población rural la más fuertemente afectada?

Dos: El libro se centra en expresiones de lo político rural y de las resistencias campesinas en concreto. En ese sentido, forma parte de una veta de estudios emergente, menos frecuente de los que uno quisiera y de los que la realidad nuestra requiere y amerita. Es el campo de las resistencias, de las acciones colectivas, de las propuestas concretas y cotidianas que construyen mujeres, hombres, jóvenes y niños, en lugares marginales, distantes del centro, desde el cual se mira, se comprende y se referencia el país. Esa réplica continua y soberbia del centralismo y de la ciudad como paradigma del progreso, va de la mano de la marginalización, la invisibilidad y el desprecio por esos otros, por el resto, por la provincia y, por supuesto por el campo.

Silva Prada reconstruye lecciones de lo político desde las márgenes del Carare y del Cimitarra. Lecciones de dignidad desde actores inesperados que desafían los marcos de construcción de lo político, lecciones que nacen acompañadas de un proceso profundo de territorialización, desde el cual se fortalece la construcción de un nosotros. Se trata de procesos que de manera simultánea son fin, medio y justificación para situarse no solo física, sino social y políticamente frente al país. Lo rural, en tanto lugar antropológico tiene que ver profundamente con la práctica del habitar, que supone ser-estar-ahí, para configurar un sentido de lugar que es fundamental como referente de pertenencia colectiva, como ubicación en lo global y como sentido diferenciador con los otros.

Centrarse en la dimensión política de los campesinos, plantea el reto de reconocerlos más allá del usual papel como productores de alimentos y cuidadores de recursos naturales. Es comprender que habitar el campo es también una opción digna de vida y no solo un error. Que el campo, que lo rural, es fuente de patrimonio cultural y capacidad de lucha social, de reivindicación y de construcción de autonomía. Así, el territorio se erige en el lugar de la diferencia, de la alteridad socio-cultural, que afirma una forma de vida y reconfigura sus múltiples relaciones y desde el cual es posible confrontar los intereses de un sistema que cada vez evidencia sus propios límites. Paradójicamente, dicho sentido de lugar se constituye desde condiciones muy adversas, no solo por las condiciones materiales de vida, sino por la profundidad de la violencia y de los conflictos de diverso orden.

Tres: Las dos experiencias organizativas rurales, la del Valle del Cimitarra y la del Carare, son construidas por poblaciones profundamente sacudidas por la guerra. Son sobrevivientes, que desde su dignidad moral en tanto víctimas, 
alzan su voz, construyen propuestas cotidianas para vivir mejor. Y como dice Reyes Mate, las víctimas no ven lo mismo que los demás...la sociedad necesita la guía moral de la mirada de las víctimas, pues el sufrimiento que ellas pueden desvelar escapa al análisis de los políticos (2005).

Las dos asociaciones campesinas se piensan a sí mismas, pero también se proyectan y dialogan con la región y con el país a través de redes, de las cuales se ocupa Diego Fernando en el libro. Ambas han sido reconocidas a nivel nacional e internacional por su aporte en la construcción de la paz, por su capacidad para crear desde la destrucción y el dolor. Y no es para menos. Sumadas las condiciones de aislamiento y de empobrecimiento continuo, están la estigmatización y señalamiento, los asesinatos y persecuciones en el marco de la guerra, que potencia la adversidad para vivir, sobrevivir y, cómo no, para proponer. Las lecciones de persistencia y de terquedad para buscar desde esas condiciones fuerza moral y decisión para ir mucho más allá de la sobrevivencia a la propuesta, constituyen sin duda un profundo ejercicio político. No olvidemos que para muchas comunidades rurales, la guerra les ha implicado un cambio en sus demandas sociales e inclusive en sus repertorios. Ha significado bajar su perfil organizativo, posponer reivindicaciones de orden estructural como la redistribución de la tierra, para situarse en la defensa básica de la vida y a las urgencias propias de "volver a empezar" luego del destierro y el despojo y, en muchos casos, incluso la disolución y fragmentación de sus procesos y vínculos de confianza y vecindario.

El sesgo rural que ha tenido la guerra, la cual se libra en la mitad o menos del territorio nacional, ha impactado directamente en una parte de la población colombiana, territorio y población usualmente rurales. Por ello, es posible que las mayorías urbanas puedan abstraerse con cierta facilidad de la guerra y la sitúen como un problema ajeno, externo y, lo que es peor, que terminen responsabilizando por acción u omisión a las víctimas. Las solidaridades escasas, y nada sostenidas, se dispersan en medio de la cotidia- nidad y de la apariencia de normalidad que disfrutamos los citadinos.

Las víctimas, los sobrevivientes, son en una alta proporción pobladores rurales, indígenas, afrodescendientes y campesinos, cuyo recomenzar en condiciones tan adversas es todo un desafío para el Estado y la sociedad. Víctimas que son revictimizadas por las promesas institucionales incumplidas, por las nuevas amenazas que sufren, por la incertidumbre de cada día, buscando rehacer sus vidas y las de sus familias. $\mathrm{Y}$ los efectos de estas vulneraciones son largos y perniciosos en el tiempo y sus consecuencias sobreviven con mucho al conflicto en si una vez superado. No es posible alcanzar la paz social sin la reparación de los derechos de las personas (Barnes, 2006).

Cuatro: Señalaría también que el libro de Silva Prada da muestras de capacidad y franqueza para compartir de manera clara y autocrítica su caminar metodológico, no como una segura autopista, sino más bien como una trocha frágil e incierta que se fue construyendo en el proceso mismo. Las reflexiones sobre el quehacer investigativo con todas las dudas y prejuicios es un testimonio enriquecedor en términos metodológicos para compartir con los otros. Ese ejercicio es más bien escaso en el medio académico en general, pues con frecuencia buscamos, con cierta soberbia, exaltar y reinventar éxitos y certezas inexistentes en la construcción de conocimiento. Las dinámicas cotidianas que fueran permitiendo edificar confianza entre los miembros de las comunidades y el investigador son, a mi juicio, sencillas pero complejas construcciones sociales, imprescindibles para lograr comprender los invisibles hilos que dan forma a un tejido social suficientemente fuerte para afrontar las duras realidades y los desafíos frente a la violencia y a la búsqueda de alternativas de desarrollo. Es muy útil que los avatares de esos recorridos los haya planteado el autor de manera abierta, incluyendo sus temores, sus opciones y sus desencuentros entre sus estereotipos y las realidades con las cuales se encontró. De igual utilidad resulta la explicación de las categorías y el manejo del material recogido, una etapa que 
con frecuencia queda ignorada, en tanto trastienda o cocina de la investigación; además de tener un enorme y complejo trabajo, este es un tiempo clave que da forma a un texto coherente y organizado como este libro.

Cinco: Finalmente, quiero resaltar que el estudio realiza un ejercicio de contraste de dos casos y el manejo acertado y fluido para discutir lo teórico con lo empírico. Sin ser en sentido estricto una apuesta de tipo comparativo clásico, el autor además de caracterizar los dos casos ya mencionados, dialoga y discute los conceptos analíticos con las realidades que le dan soporte. Las dinámicas de violencia social y política/ construcción de paz/ desarrollo en tanto líneas transversales, así como los conceptos de territorialidad, desterritorialización, autonomía, resistencia civil, entre otros, que se despliegan en varios capítulos constituyen aciertos teóricos que facilitan y permiten profundizar en el sentido y contribución de estos procesos sociales de comunidades campesinas.

Por supuesto, realidades tan interesantes como las trabajadas por Diego Fernando pueden abordarse desde muchos lugares conceptuales y parte del desafío del investigador es poder delimitar y optar por unas categorías, dejando de lado otras que van emergiendo, que no siempre es fácil dejar al margen. Como lectora, me surgen diversas preguntas y tentaciones de discusiones más amplias y profundas sobre varios temas. Es el caso, por ejemplo, de las tensiones y conflictos internos y externos sobre los cuales no es fácil ni preguntar ni obtener respuestas. Como lo señala Flórez (2010), es importante comprender de qué manera los movimientos sortean las crisis y los disensos en tanto parte constitutiva de su acción política, de modo que las relaciones internas de poder no pasen a ser de dominación. También me genera interés especial ampliar la discusión en torno a la dimensión compleja sobre las trampas de los discursos del desarrollo y la forma en que estos procesos colectivos las sortean, la resignifican y recrean, como parte del ejercicio mismo de construcción y decisión política. Y, por qué no mencionar aquí también, la pregunta por la manera como estas asociaciones han valorado y usado este trabajo que las analiza.

Estas y muchas otras preguntas que suscitará en los lectores este libro, serán fuente de inspiración y discusión para nuevos estudios. 


\section{Referencias bibliográficas}

Barnes, J. (2006). "Sobre la reparación patrimonial de los desplazados y la restitución de la propiedad en el contexto de la justicia transicional" En: Tutelando los derechos, Respuestas institucionales y sociales al desplazamiento forzado. Bogotá: Codhes.

Flórez, J. (2010). Lecturas emergentes: Decolonialidad y subjetividad en las teorías de movimientos sociales. Bogotá: Universidad Javeriana.
Mate, R. (2005). A contraluz de las ideas politicamente correcta. Barcelona: Anthropos.

PNUD. (2011). Informe Colombia Rural. Razones para la esperanza. Recuperado de http://pnudcolombia.org/indh2011/index.php/elinforme/informe-completo

Silva Prada, D. F. (2011). Asociaciones campesinas en resistencia civil. Construcción de pazy desarrollo en el Magdalena Medio. Bogotá: Uniminuto. 